\title{
Computational and Experimental Comparison of a Powered Lift, Upper Surface Blowing Configuration
}

\author{
Jay Marcos ${ }^{*}$ and David D. Marshall ${ }^{\dagger}$ \\ California Polytechnic State University, San Luis Obispo CA 93407-0352
}

\begin{abstract}
This paper demonstrates the use of CFD as a validation tool for wind tunnel data on 2D high lift airfoil with a 3D engine performed by Georgia Tech Research Institute. Results of this validation will assist in determining the appropriate turbulence models, boundary conditions, mesh characteristics and other CFD modeling techniques necessary to capture the complicated flow physics associated with the coupling of circulation control wings and engine exhaust flows. It was found that grid issues and the two-equation turbulence model, $k-\varepsilon$, over predicted lift as blowing momentum increases even with the additional complexity of having an over the wing engine. The detailed techniques utilized to most accurately capture the flow properties, including lift forces and flow field characteristics, are provided and discussed.
\end{abstract}

\section{Nomenclature}

$\begin{array}{ll}\text { A } & =\text { Area } \\ \text { C } & =\text { Chord length } \\ C_{L} & =\text { Lift coefficient } \\ C_{D} & =\text { Drag coefficient } \\ C_{\mu} & =\text { Blowing momentum coefficient } \\ C_{T} & =\text { Thrust coefficient } \\ D & =\text { Engine nozzle diameter } \\ e_{a p p} & =\text { Approximate relative error } \\ e_{\infty} & =\text { Extrapolated relative error } \\ G C I & =\text { Grid convergence index } \\ h & =\text { Average mesh size } \\ k & =\text { Turbulent kinetic energy } \\ \dot{m} & =\text { Mass flow rate } \\ n & =\text { Order of solution } \\ N & =\text { Total number of cells } \\ P & =\text { Static pressure } \\ q & =\text { Dynamic pressure } \\ r & =\text { Grid refinement factor } \\ R & =\text { Gas constant }\end{array}$

$S$
$T$
$V$
$X$
$Z$
Greek Symbols
$\alpha$
$\Delta V$
$\varepsilon$
$\phi$
$\omega$
Subscripts
$\infty$
$C F D$
exp
eng
slot
1
2
3

$=$ Wing planform area

$=$ Static temperature

$=$ Velocity

$=\mathrm{x}$-location

= z-location

$=$ Angle of attack

$=$ Cell volume

$=$ Turbulent dissipation rate

$=$ Key variable

$=$ Specific dissipation rate

$=$ Freestream

$=$ Computational fluid dynamics

$=$ Experimental

$=$ Engine conditions

$=$ Slot conditions

= Coarsest mesh

$=$ Intermediate mesh

$=$ Finest mesh

\footnotetext{
* Student, Aerospace Engineering Dept. Student Member.

${ }^{\dagger}$ Associate Professor, Aerospace Engineering Dept. Senior Member.
} 


\section{Introduction}

$\mathrm{T}$ HE intent of this paper is to show the development and advantages, as well as disadvantages, of using computational fluid dynamics as a validation tool for existing wind tunnel experimental data of a 2D high lift airfoil with a 3-D engine performed by Englar et. al. ${ }^{1}$ at Georgia Tech Research Institute (GTRI). Figures (1) shows the GTRI model equipped with circulation control wings (CCW) and upper surface blowing (USB) from the engine. The motivation behind this validation is to develop grid generating and solving techniques that will be applied to future CFD analysis of other aircraft configurations from the NASA Research Announcement (NRA) project. One of the primary purposes of the NASA contract is to develop the predictive capabilities ${ }^{2}$ for the design and performance of a 100 passenger $\mathrm{N}+2$ generation cruise efficient, short take-off and landing subsonic aircraft configuration. The chosen configuration will utilize CCW as high lift devices ${ }^{3}$ to achieve the short take-off and landing capabilities of the aircraft ${ }^{4}$. The main tasks GTRI sought to achieve with the wind tunnel experiments were to gain thorough understanding of geometric and pneumatic interactions between CCW and USB or over the wing (OTW) powered lift ${ }^{5}$ as well as perform dual-radius $\mathrm{CCW}^{6}$ flap experiments with and without blowing.

To accurately perform CFD analysis on the GTRI model, Ansys ICEM $11.0^{7}$ will be utilized to construct a combination of structured and unstructured meshes to accurately discretize the flow domain. With the appropriate boundary conditions and solver settings, Ansys FLUENT $6.3^{8}$ will then be used to solve for the governing

equations of momentum, mass, and energy Figure 1: Typical high-lift, USB configuration. within the generated mesh.

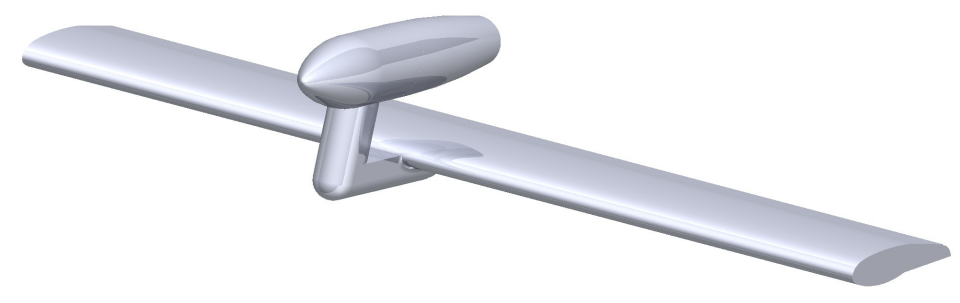

\section{Wind Tunnel Experiment}

Georgia Tech Research Institute has conducted experimental studies on pneumatic powered circulation control wings with engines located over the wing to improve powered high-lift and cruise performance of a cruise efficient short takeoff and landing (CESTOL) aircraft configuration'. The integration of these systems provide very high lift for short takeoff and landing, low thrust recovery for approach, and high thrust recovery for takeoff and climb while minimizing mechanical complexity. The purpose of these evaluations was to develop the most effective pneumatic aerodynamic and propulsive geometries with minimal noise production ${ }^{1}$.

To perform the necessary aerodynamic, propulsive, and acoustic evaluations, the model was equipped with different components that allow for variable thrust coefficient, blowing momentum coefficient, blown flap angle, blowing slot height, engine horizontal $(x / C)$ and vertical $(z / D)$ location over the wing, engine thrust deflection, wing leading-edge device, angle of attack, and Reynold's number. Figures (2)-(4) shows the different parts necessary in accomplishing the variability of the different parameters of the model.

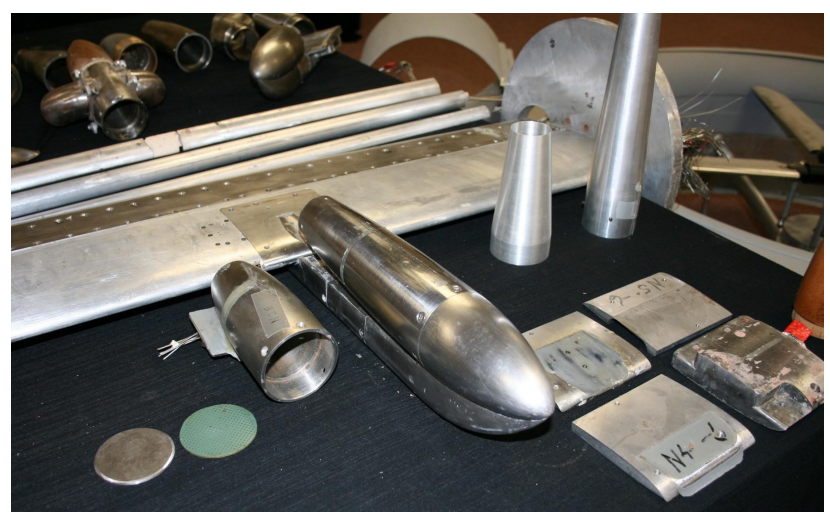

Figure 2: Front view of OTW engine simulator by Englar et. al. ${ }^{1}$ 


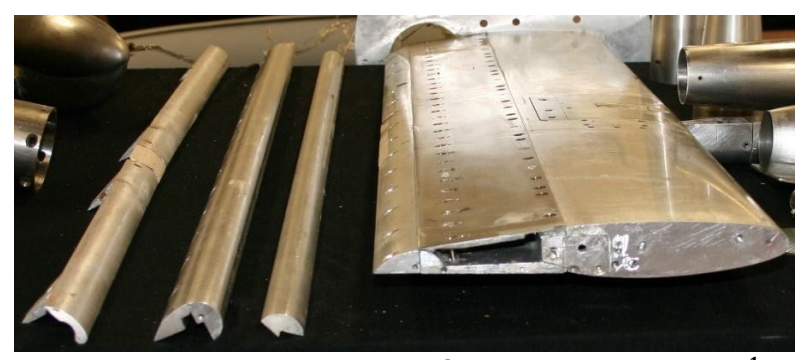

Figure 3: CCW trailing edge flaps by Englar et. al. ${ }^{1}$

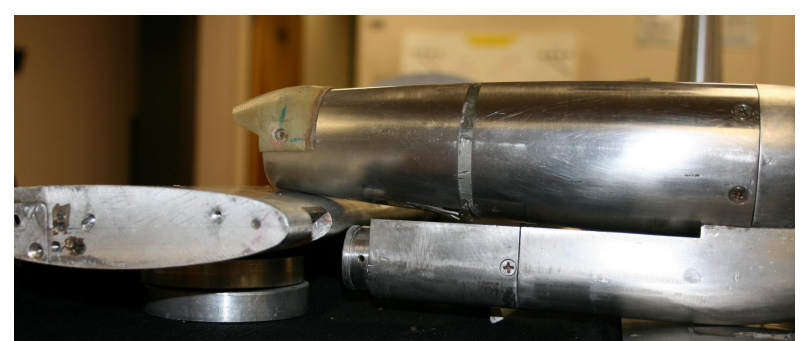

Figure 4: $15^{\circ}$ thrust deflector installed on engine by Englar et. al. ${ }^{1}$.

Initial aerodynamic and propulsive testing of each powered-lift configuration was performed in GTRI's Model Test Facility (MTF). Figures (5) and (6) shows a typical configuration installed in the MTF's six component floor balance. The wing of the model extends from the floor to the ceiling to simulate a 2D airfoil and eliminate wing tip effects while still having effects of a 3D engine. The configuration that exhibits the best aerodynamic, propulsive, and acoustic performance will be incorporated with a large scale, 3D powered-lift, and over the wing configuration to be tested in a large scale wind tunnel. Although acoustic performance were evaluated for each configuration, this paper will only discuss the validation of the aerodynamic and propulsive performance results.

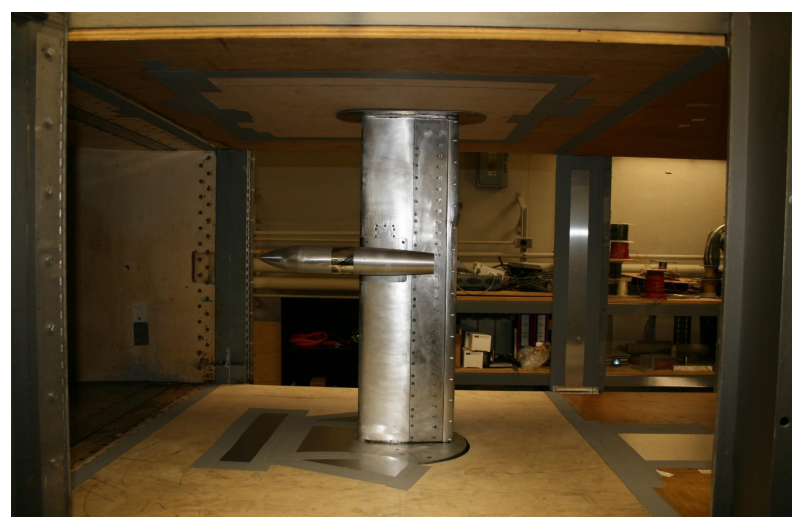

Figure 5: Configurations A installed in GTRI's MTF tunnel by Englar et. al. ${ }^{1}$

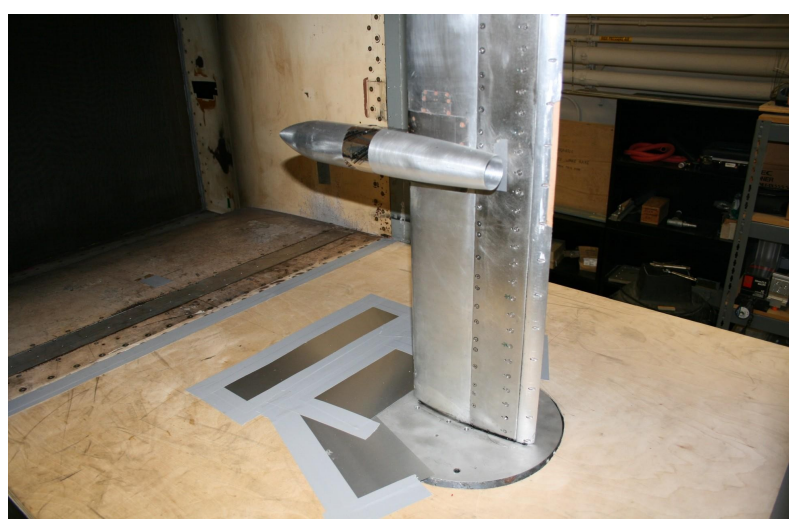

Figure 6: Configuration A with engine at $\mathrm{x} / \mathrm{C}=\mathbf{0 . 7 5}$, $\mathrm{z} / \mathrm{D}=\mathbf{0 . 2 3}$ and $0^{\circ}$ flap deflection by Englar et. al. ${ }^{1}$

\section{Grid Generating Methods}

Before the governing equations for mass, momentum, and energy can be solved, an appropriate mesh will be generated to discretize the flow domain of the model. The mesh will consist of a surface mesh on the model, a boundary layer mesh to accurately model the viscous forces, and a volume mesh that will cover all parts of the flow domain.

To more accurately match the experimental conditions, the simulation was performed with the presence of wind tunnel walls as opposed to free air to capture wall effects. This meant that the dimensions of the flow domain around the CFD model had to be the same as the dimension of the MTF, 30x43x90 in. Figure (7) shows the CFD model inside the flow domain where the mesh will be constructed. The additional lengths located at the front and behind the "wind tunnel” walls will act as a "symmetry" boundary condition to straighten the flow entering the "wind tunnel." 


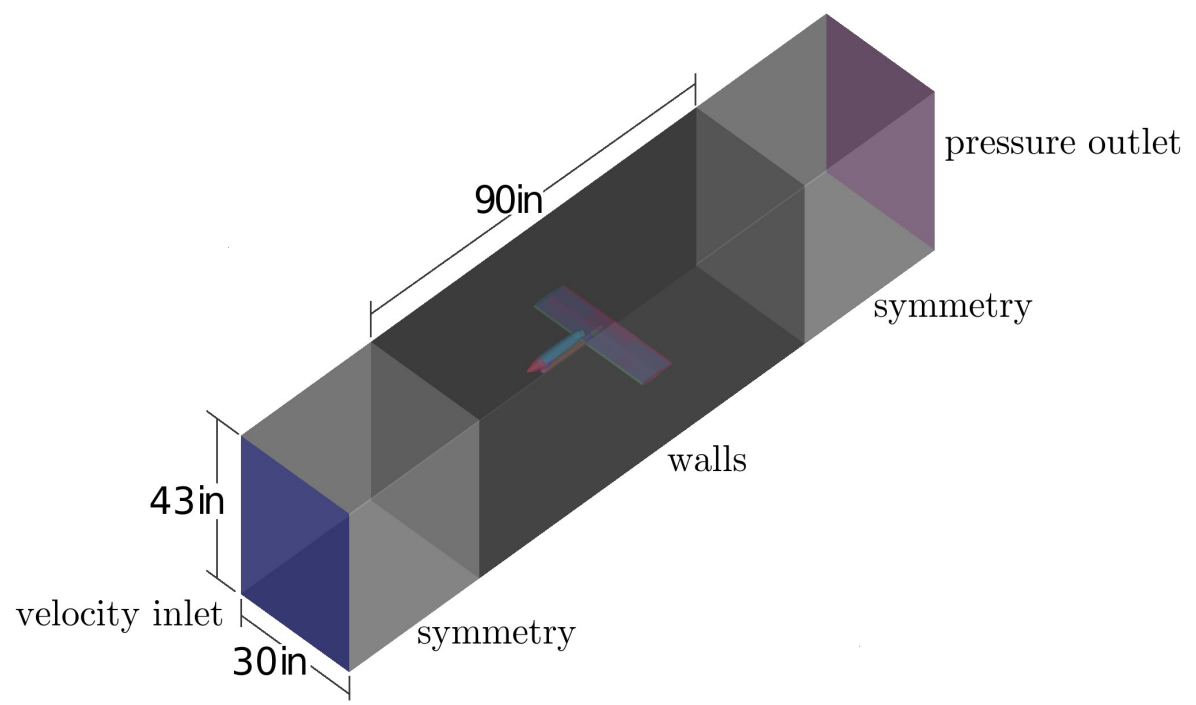

Figure 7: Flow domain representing the wind tunnel walls to capture wall effects.

\section{A. CAD/Geometry}

A computer aided model of GTRI's configurations was first generated before meshing could begin. The completed 3D model was imported as a .stp file that the meshing software could recognize. The model was then broken up into different parts, allowing for a mesh with different cell sizes. This could limit the number of smaller cells to a particular region on the model that would be experiencing high flow property gradients, minimizing the overall cell count. Figure 8 shows a typical configuration broken up into different parts and ready for surface meshing.

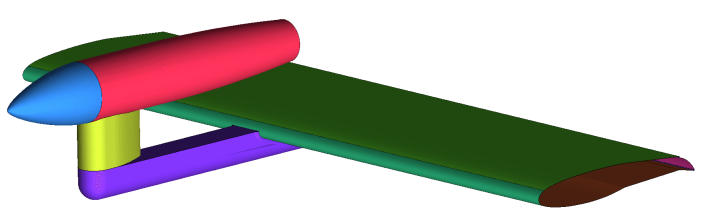

\section{B. Unstructured Surface Mesh}

Accurately sizing the surface mesh not only defined the shape of the model but it also captured the high flow property gradients caused by the blowing of the engine and the CCW. It was important to keep in mind that the quality and the number of cells could greatly decrease the convergence time during the solution process and could also affect the accuracy of the solution. The surface mesh affected the quality of the volume mesh that was generated because the transitioning of smaller cells to larger cells on the surface determined the growth rate of the volume mesh. Since accuracy of the solution was dependent on the sizes and growth rate of the cells, it was essential that these properties of the surface mesh was carefully generated. Figure 9 shows the smaller cells on the leading edge as it transitions into larger cells towards the upper surface of the wing. Breaking the model into different parts became helpful because it allowed for cell refinement around a more complex geometry like the leading edge and cell coarsening on top of the wing, a less complex geometry feature. Other geometry topologies to consider when sizing the surface mesh were the front of the engine and the

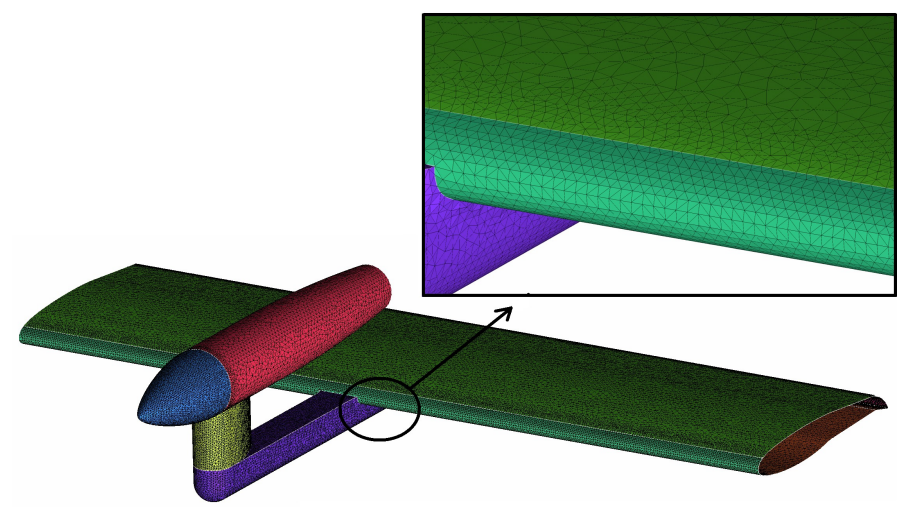

Figure 9: Leading edge surface mesh. 
back of the engine support. The symmetrical airfoil-like shape of the engine support required smaller cells to capture the geometry at its trailing edge.

Understanding of the flow features also aided in the sizing of the surface mesh. The flow above and the wing was expected to experience small flow property gradients which allowed it to be modeled with coarser cells. However, the blowing of air out of the CCW slot would cause the top surface of the trailing edge to experience high flow property gradients, suggesting that smaller cells were necessary to capture those changes. Figure 10 shows the smaller cells on the trailing edge surface to capture the high flow property gradients. Majority of the experiments depended on the

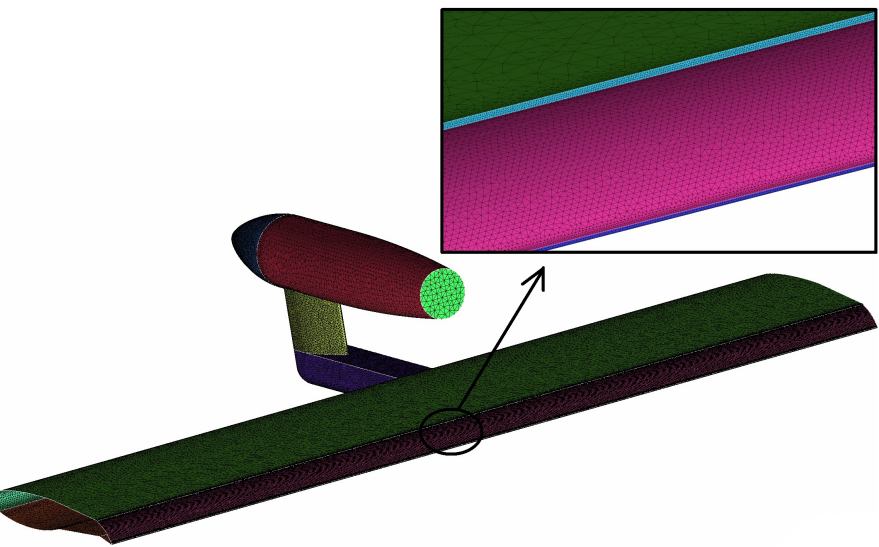

Figure 10: Trailing edge surface mesh. variations in the conditions of the circulation control slot at the trailing edge. Therefore, it was very important that this slot was adequately resolved in order to capture a high resolution flow field. In general, the slot height was captured with roughly 5 or more elements.

\section{Unstructured Volume Mesh}

To accurately capture the flow properties, the whole domain also had to be discretized in order for the CFD solver to solve for the governing equations. The choice of the type of mesh to employ, structured or unstructured, directly affected the accuracy of the solution as well as the time of convergence. There were advantages and disadvantages in using either structured or unstructured mesh. Generating a structured mesh with hexahedral elements proved to be computationally quicker because the way the cells were physically oriented throughout the whole domain. Majority of the cells would be oriented in the direction of the freestream, which not only made it faster for the CFD solver to solve for the governing equations but it also greatly reduce the numerical diffusion of the solution. However, the use of a structured mesh for the domain required structured elements on the surface of the model as well. With the mesh generator Ansys ICEM 11.0, it was much more difficult to generate structured elements to capture the complex geometries of the model. Even if structured elements were generated on the surfaces of the model, using a structured mesh will increase the non-orthogonality or skewness of the cells. It was much more computationally extensive to solve for these skewed cells. Using an unstructured mesh decreased the amount of skewed cells but it increased the numerical diffusion of the solutions and increased the total number cells throughout the whole domain.

For reasons stated in the preceding paragraph, an unstructured mesh was used for the flow domain. Constructing a good mesh near the model was important as it presented high flow property gradients and a lot of unsteadiness in the numerical solution. With Ansys ICEM , the process of generating an unstructured volume mesh was simplified by providing user friendly options that generated the mesh in a small amount of time. Figure 11 shows the unstructured tetrahedral cells generated by the Octree method. The Octree algorithm in Ansys ICEM assured that cell refinement was performed where necessary while constructing coarser cells wherever possible. This method meshes the outer domain first before generating smaller cells to capture the complex geometry of the model.

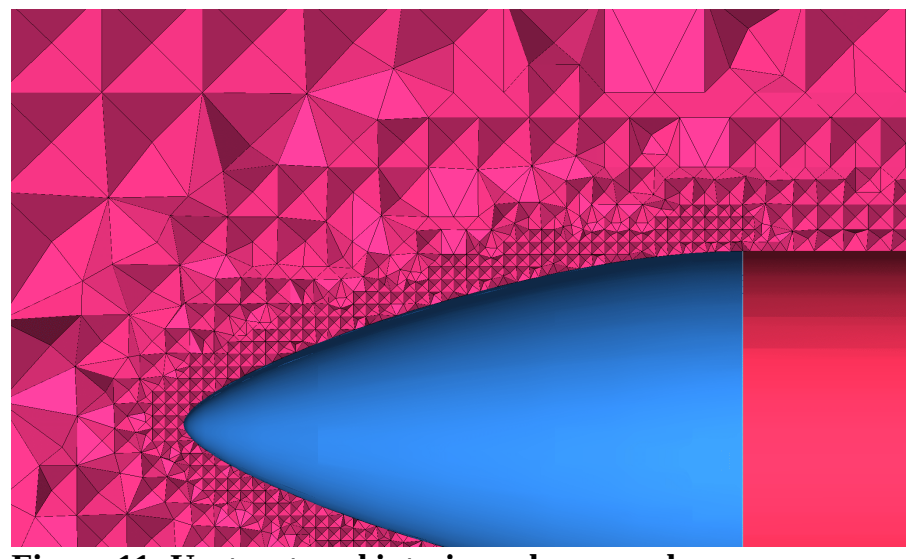

Figure 11: Unstructured interior volume mesh. 


\section{Boundary Layer Mesh}

Capturing the near wall flow features was done with a good quality boundary layer mesh. The most efficient choice for creating a boundary layer mesh was to grow triangular prisms from the surface triangles, which allowed the prisms to be oriented parallel to the surface and in the direction of the flow. The orientation of the prisms could accurately capture the growth of the boundary layer while still minimizing computational errors. The use of tetrahedral cells for boundary layer mesh was avoided precisely because of this reason.

The quality of the boundary layer mesh was highly dependent on several factors: the cell shape in terms of aspect ratio, skewness, and warp angle. Poor quality in any of these elements could result in instability of the simulation as well as inaccuracy of the results. The user had the ability to directly control the aspect ratio of the cells by specifying the initial height and growth ratio of the prisms. The length of the base of the prism was predetermined by the size of the surface mesh, since the prisms were generated from the triangular cells. Therefore, when sizing the surface mesh, it was convenient to consider the prism layers that would be grown on it. The user also had some ability in improving the skewness of the prisms by using the built in smoothing algorithms of the grid-generation software. Since the boundary layer mesh was constructed after the unstructured volume mesh, the quality of the volume mesh greatly impacted the quality of the boundary layer mesh.

Figure 12 shows the boundary layer mesh grown on the surface of the model transitioning into the unstructured volume mesh. It's important to note that the accuracy of the solution was also affected by the transition of the boundary layer mesh into the the unstructured volume mesh. To ensure a good volume transition of the prism mesh, each prism layer normally had a growth ratio of $40 \%$ and the last prism element had a roughly 1:1 volume ratio to the adjacent tetrahedral element.

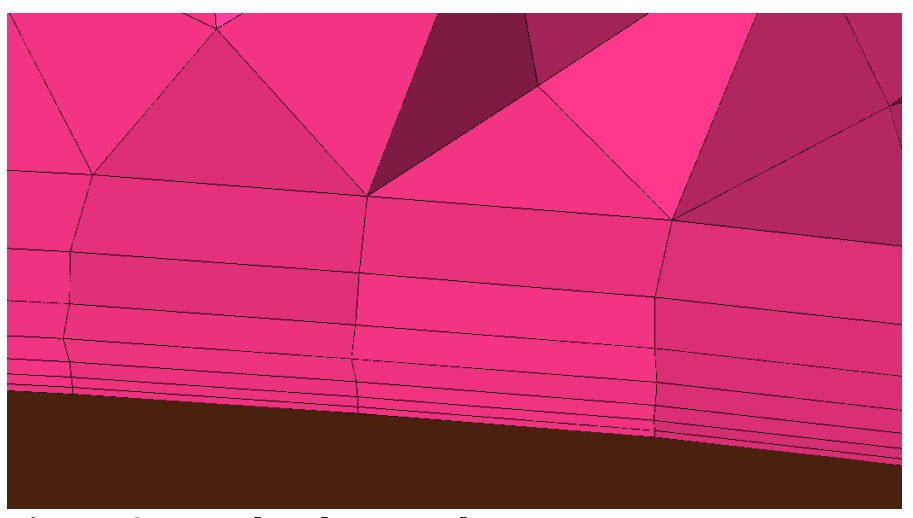

Figure 12: Boundary layer mesh.

\section{E. Grid Independence Study}

In order to perform a grid independence study, at least three different size meshes was generated in order to utilize the Richardson's extrapolation method. The grid elements were proportional in size for all three meshes and the same method was used to generate the meshes for all three cases. Ansys ICEM allowed the user to specify the cell sizes at different parts of the surface mesh as well as the volume mesh. Also, it allowed the user to scale these sizes collectively by changing the "Global Element Scale Factor" instead of scaling each cell size individually. ICEM script files were generated to ensure that the process of meshing each case was identical. To create a scaled mesh, the "Global Element Scale Factor" was simply adjusted in the script files and was then read in by ICEM. However, The "Global Element Scale Factor" did not change the number of elements by the same factor. A factor of 0.5 doesn't necessarily correspond to a mesh with twice as many cells. The attempt of creating meshes with twice as many cells and half as many cells than the original mesh proved to be quite difficult even with the help of script files. Instead, a fine mesh was created using a scale factor of 0.34 which generated $20 \%$ more cells while a coarse mesh was created using a scale factor of 1.72 which generated $45 \%$ less cells. More work will be going into refining this process in order the refine the grid convergence study.

\section{Numerical Simulation}

\section{A. Solver Settings and Boundary Conditions}

Once a good quality mesh had been generated throughout the entire domain, the mesh file was loaded into the CFD solver, FLUENT 6.0. Before the governing equations could be solved, the appropriate settings was first enabled throughout FLUENT's interface and the correct boundary conditions was specified to accurately match the conditions in which the experimental evaluations were performed. Table 1 shows the list of typical solver settings and boundary conditions used for this validation. To more accurately match the experimental conditions, the simulation was performed with the presence of wind tunnel walls as opposed to free air. 


\section{B. Turbulence Model Selection}

A 2D CCW airfoil study was performed by Storm and Marshall ${ }^{10}$ to determine the best turbulence model for simulating the flow features affected by circulation control. The study was to determine which of FLUENT's existing turbulence models, Spalart-Allmaras ${ }^{11}, k-\varepsilon^{12}$, or $k-\omega^{13}$, performed best for this type of simulation. It was found that the $k-\varepsilon$ turbulence model, which was designed to be applied throughout the boundary layer provided a high quality near wall mesh, is the most accurate in capturing turbulence features of CCW airfoils. However, the general trend of twoequation turbulence models, such as the $k$ - $\varepsilon$ turbulence model, is to over-predict $C_{L}$ as $C_{\mu}$ increases. How this trend was affected by the added complexity of the engine will be discussed in the Results section..

Storm and Marshall are also developing a modified $v^{2}$-f turbulence model to capture the nonlinear eddy viscosity effects and streamline curvature effects of circulation control flows ${ }^{14}$. The modified $v^{2}-f$ turbulence model is currently in its validation stages. Until this model is finalized, the $k-\varepsilon$ turbulence model will be utilized for this project.

\section{Table 1: Fluent solver settings and boundary} conditions.

Fluent 6.3 Solver Settings

\begin{tabular}{ll}
\hline Turbulence Model & Standard $k-\varepsilon$ \\
solver & Compressible \\
Density Calculator & Ideal-gas Law \\
Viscosity Calculator & Sutherland's Law \\
Engine Outlet & mass flow inlet \\
CCW Outlet & mass flow inlet
\end{tabular}

Freestream Conditions

\begin{tabular}{lr}
\hline Pressure (psi) & 14.7 \\
Velocity (ft/s) & 68 \\
Mach Number & 0.06 \\
Temperature (R) & 534.65
\end{tabular}

\section{CFD model}

Engine

\begin{tabular}{lr}
\hline Pressure (psi) & 13.98 \\
Mass Flow Rate (slugs/s) & Varying \\
Temperature (R) & 600.76
\end{tabular}

\begin{tabular}{lr}
\multicolumn{2}{c}{ TE CCW } \\
\hline Pressure (psi) & 13.98 \\
Mass Flow Rate (slugs/s) & Varying \\
Temperature (R) & 600.76
\end{tabular}

The primary purpose of Georgia Tech Research Institute's experimental modeling was to determine the effects of OTW engine location relative to the blown trailing edge, as well as the effects of variations in thrust coefficient and the CCW slot blowing coefficient on force and moment generation. This led GTRI to evaluate the aerodynamic and propulsive performance of 37 different wind tunnel models shown in Appendix A. Although GTRI performed aerodynamic and propulsive tests on 37 configurations, performing CFD analysis on only one configuration was sufficient for this validation. GTRI's Configuration B was chosen as the CFD model because of its simple characteristics: no flap deflection, no leading edge devices, and no hood angle. Figure 13 shows a diagram of Configuration B. 


\section{Configuration $B: \frac{X}{C}=0.03, \frac{X_{t e}^{*}}{D}=5.25, \frac{Z}{D}=0.37$}

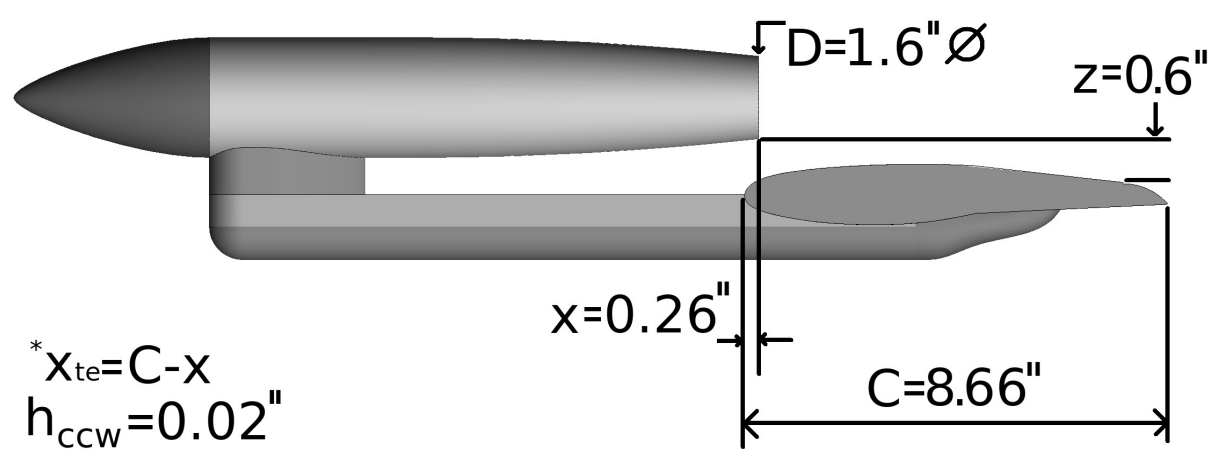

Figure 13: Geometry specifications of Configuration B.

\section{D. $C_{\mu}$ and $C_{T}$ calculation}

The given experimental data used to determine the boundary conditions included values for dynamic pressure, $q$, slot blowing coefficient, $C_{\mu}$, and thrust coefficient, $C_{T}$. A "mass-flow-inlet" boundary condition was set for the slot and the engine in FLUENT, which required a mass flow rate, $\dot{m}$, to be inputted in the settings. Values for $\dot{m}$ were calculated from the reported experimental $C_{\mu}$ and $C_{T}$ using

$$
\begin{aligned}
& \dot{m}_{\text {slot }}=\sqrt{\frac{C_{\mu \exp } P_{\infty} A_{\text {slot }} q_{\infty} S}{R T_{\infty}}} \\
& \dot{m}_{\text {eng }}=\sqrt{\frac{C_{T \exp } P_{\infty} A_{\text {eng }} q_{\infty} S}{R T_{\infty}}}
\end{aligned}
$$

where $A$ is the slot area, $S$ is the wing planform area, and $R$ is the gas constant. After specifying a $\dot{m}$ and the rest of the boundary conditions, the simulation was performed. The numerical $C_{\mu}$ was then calculated using the velocity at the exit plane of the slot and engine with the following equation

$$
\begin{aligned}
& C_{\mu C F D}=\frac{\dot{m}_{\text {slot }} V_{\text {slot }}}{q_{\infty} S} \\
& C_{T C F D}=\frac{\dot{m}_{\text {eng }} V_{\text {eng }}}{q_{\infty} S}
\end{aligned}
$$

In FLUENT, the velocity at the slot and the engine, $V_{\text {slot }}$ and $V_{\text {eng }}$ respectively, can be directly obtained from the results. However, in wind tunnel experiments, measuring the actual velocities at the slot and engine can be quite difficult. Traditionally, these velocities are approximated using the known measurement of mass flow rate and freestream density instead of the actual density outside the slot or engine as seen from the following expressions 


$$
\begin{aligned}
& V_{\text {slot } \exp }=\frac{\dot{m}_{\text {slot }}}{\rho_{\infty} A_{\text {slot }}} \\
& V_{\text {eng } \exp }=\frac{\dot{m}_{\text {eng }}}{\rho_{\infty} A_{\text {eng }}}
\end{aligned}
$$

\section{E. Grid Independence Study Using Richardson's Extrapolation}

To perform a grid independence study, Richardson's extrapolation was used to determine the grid convergence index, GCI, and the extrapolated solution if an infinitely large mesh size was used. This method is applicable to a study using three different meshes, which are all proportional in size. Celik et. al. ${ }^{15}$ recommended the following procedure for estimating the discretization error. First the average mesh, $h$, was determined from the following equation

$$
h=\left[\frac{1}{N} \sum_{i=1}^{N} \Delta V_{i}\right]^{1 / 2}
$$

where $\Delta V$ is the volume of the $i^{\text {th }}$ cell and $N$ is the total number of cells. As a measure of refinement from one grid to the next, the grid refinement factor, $r$, was calculated using

$$
r_{i j}=\frac{h_{i}}{h_{j}}
$$

where $i$ corresponds to the coarser grid and $j$ corresponds to the finer grid. The apparent order, $n$, of the method was then calculated using the expression

$$
n=\frac{1}{\ln r_{23}} \ln \left[\left(\frac{\phi_{1}-\phi_{2}}{\phi_{3}-p h i 2}\right)\left(\frac{r_{23}^{n}-1}{r_{12}^{n}-1}\right)\right]
$$

where $\phi$ is a variable important to the object of the simulation of the study. For this validation, $\phi$ represented the resulting $C_{L}$ or $C_{D}$ from the different meshes. The subscripts 1, 2, and 3 correspond to the mesh used, 1 being the coarsest and 3 being the finest. Richardson's extrapolation was then used to extrapolate the solution for an infinitely large mesh. The extrapolated solution was found from the expression

$$
\phi_{\infty}=\frac{r_{23}^{n} \phi_{3}-\phi_{2}}{r_{23}^{n}-1}
$$

The approximate and extrapolated relative errors were then found using

$$
\begin{aligned}
& e_{\text {app }}=\left|\frac{\phi_{3}-\phi_{2}}{\phi_{3}}\right| \\
& e_{\infty}=\left|\frac{\phi_{3}-\phi_{2}}{r_{23}^{n} \phi_{3}-\phi_{2}}\right|
\end{aligned}
$$


Finally, the grid convergence index was calculated using

$$
G C I=\frac{1.25 e_{a p p}}{r_{23}^{n}-1}
$$

\section{Results}

The purpose of this section is to validate the CFD simulations through comparison with the experimental data. The results will be presented, starting with the effects of variations in $C_{\mu}$ on the lift coefficient, followed by the effects of variations in $C_{T}$ on the lift and drag coefficients, then the lift curves for two different $C_{\mu}$ with the same $C_{T}$. A grid independence study using Richardson's extrapolation will also be presented.

\section{A. Lift and Drag Coefficients}

Figure 14 shows the lift variation as a function of thrust and slot blowing for Configuration B. At higher values of $C_{\mu}$, FLUENT over-predicts $C_{L}$ even more compared to lower values of $C_{\mu}$. For a $C_{T}=0$, the relative error increases from a low of $12 \%$, which occurs at the lowest $C_{\mu}$, to a max of $20 \%$, which occurs at the highest $C_{\mu}$. Similarly, for a $C_{T}=2.1$ the relative error increases from a low of $19 \%$ to a max of 23\%. Not only does FLUENT's over-prediction of $C_{L}$ increases as $C_{\mu}$ increases, but also as $C_{T}$ increases.

Although the error in $C_{L}$ increases as $C_{\mu}$ and $C_{T}$ increases, the overall trend of increasing $C_{L}$ with increasing $C_{\mu}$ is still captured. Validation of circulation control airfoils with no engine, $C_{T}=0$, reported by Jones et. al. ${ }^{16}$ shows similar results where $C_{L}$ was over-predicted but the trend of increasing $C_{L}$ with increasing $C_{\mu}$ was still captured. Turbulence models and CFD grid issues were reported as possible reasons why the CFD code failed to match the experimental results.

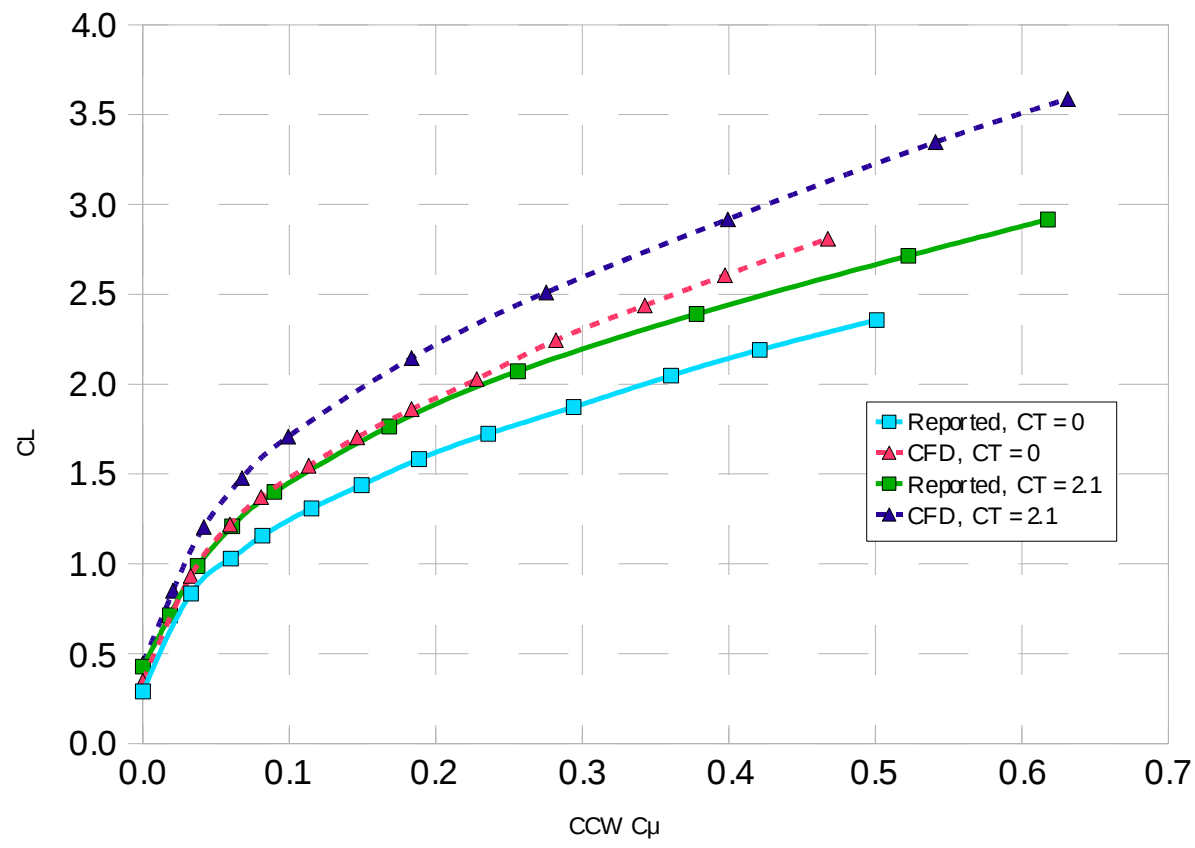

Figure 14: Configuration B lift as a function of $C_{\mu}$ at $\alpha=0$ and $q=5.5 p s f$.

Using Eq. (9), $C_{\mu}$ was calculated from the CFD results and is shown in Table (2). It's interesting to see from Table (2) that at a $C_{T}=0$ the relative error in $C_{\mu}$ increases as $C_{\mu}$ increases. However, for a $C_{T}=2.1$, the relative error decreases as $C_{\mu}$ increases. This is linked to the difference between the experimental $C_{\mu}$ and the CFD $C_{\mu}$. The experimental $C_{\mu}$ is approximated using the freestream density as the "averaged" density at the slot instead of the actual density as shown in Eq. (5). For the case where $C_{T}=2.1$, the "averaged" density at the slot is getting closer to the freestream density, therefore the CFD $C_{\mu}$ is getting closer to the experimental $C_{\mu}$. 
Table 2: Experimental and numerical slot blowing coefficient.

\begin{tabular}{cccc|cccc} 
& \multicolumn{2}{c|}{$\mathbf{C}_{\mathbf{T}}=\mathbf{0}$} & \multicolumn{4}{c}{$\mathbf{C}_{\mathbf{T}}=\mathbf{2 . 1}$} \\
$\mathbf{V}_{\text {slot }}(\mathbf{m} / \mathbf{s})$ & $\mathbf{C}_{\mu \text { CFD }}$ & $\mathbf{C}_{\mu \exp }$ & \% Error & $\mathbf{V}_{\text {slot }}(\mathbf{m} / \mathbf{s})$ & $\mathbf{C}_{\mu \text { CFD }}$ & $\mathbf{C}_{\mu \exp }$ & \% Error \\
\hline 0.00 & 0.000 & 0.000 & 0.00 & 0.00 & 0.000 & 0.000 & 0.00 \\
55.96 & 0.033 & 0.033 & 0.40 & 47.09 & 0.021 & 0.019 & 11.75 \\
75.25 & 0.059 & 0.060 & 0.80 & 66.7 & 0.042 & 0.037 & 11.40 \\
87.47 & 0.081 & 0.082 & 1.13 & 84.89 & 0.068 & 0.061 & 10.95 \\
103.4 & 0.113 & 0.115 & 1.64 & 102.49 & 0.099 & 0.090 & 10.42 \\
117.18 & 0.146 & 0.149 & 2.14 & 138.53 & 0.183 & 0.168 & 9.02 \\
130.89 & 0.183 & 0.188 & 2.68 & 168.55 & 0.275 & 0.256 & 7.54 \\
145.45 & 0.228 & 0.236 & 3.3 & 201.23 & 0.399 & 0.378 & 5.66 \\
161.05 & 0.282 & 0.294 & 4.12 & 231.88 & 0.541 & 0.523 & 3.54 \\
176.78 & 0.343 & 0.360 & 4.96 & 248.85 & 0.631 & 0.618 & 2.20 \\
189.65 & 0.397 & 0.421 & 5.66 & & & &
\end{tabular}

Figure 15 shows the lift variation as a function of thrust and blowing. Experimental results show little effect on lift from variation in $C_{T}$. FLUENT was able to capture the trend in $C_{L}$ but the relative error in $C_{L}$ increases with a higher $C_{\mu}$. For a $C_{\mu}=0$, the relative error in $C_{L}$ was about $14 \%$ while for a $C_{\mu}=0.5$ the relative error increases to $25 \%$.

Figure 16 shows the drag variations as functions of thrust and blowing. FLUENT captures the thrust recovery very well with very little relative error. The maximum error of about $7 \%$ occurs at the highest $C_{T}$ value. The coefficient of drag presented in this figure is the viscous and pressure stress contributions on the surfaces as well as the thrust components of the engine and slot.

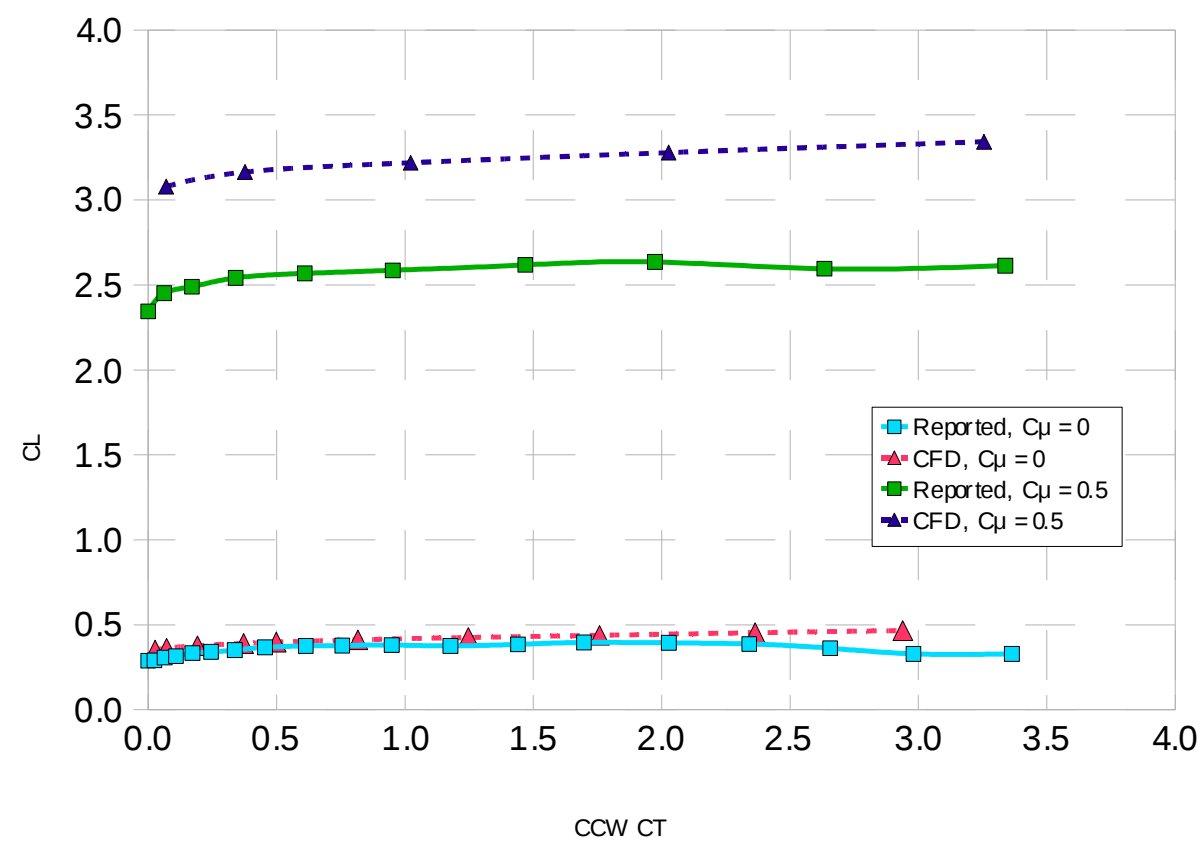

Figure 15: Configuration $B$ lift as a function of $C_{T}$ at $\alpha=0$ and $q=5.5 p s f$. 


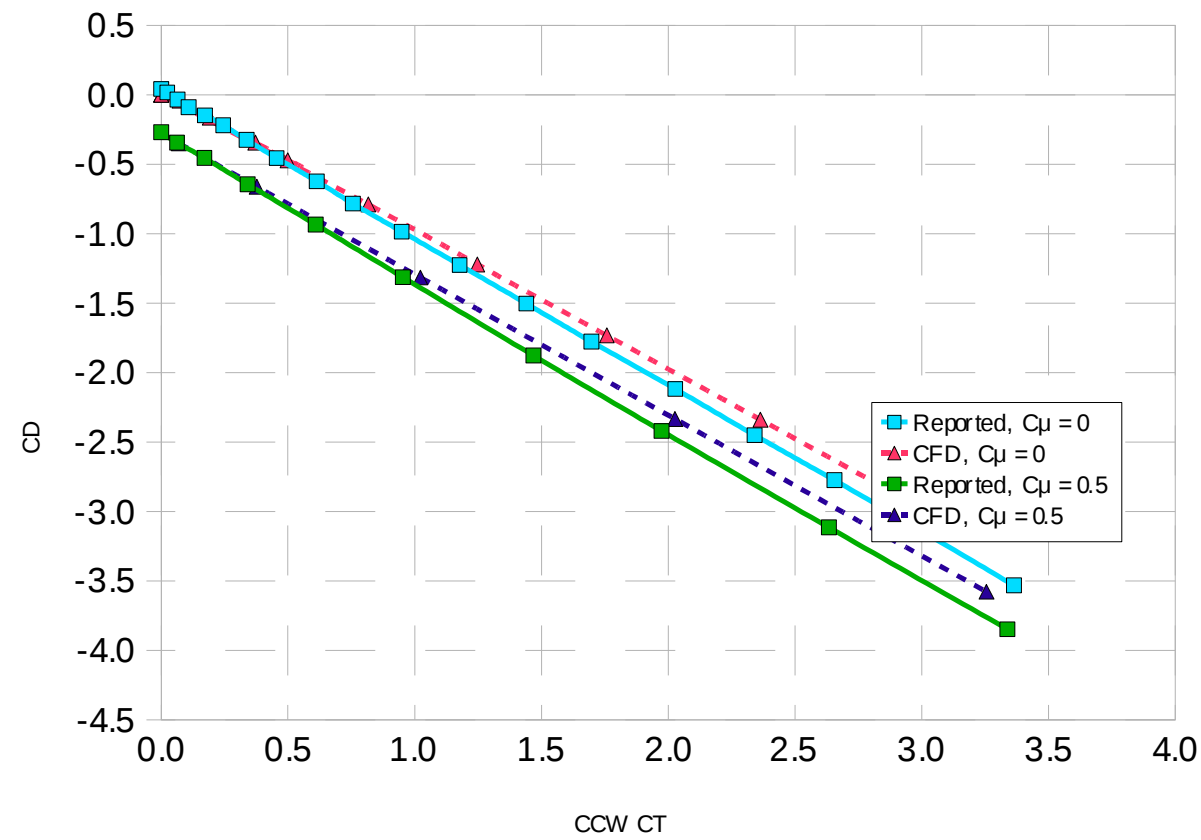

Figure 16: Configuration $B$ drag as a function of $C_{\mu}$ at $\alpha=0$ and $q=5.5 p s f$.

Table 3 shows the calculated and the experimental thrust coefficients using Eq (4). From this table, it's apparent that FLUENT matches $C_{T}$ more accurately at higher values of $C_{T}$. Even at low values of $C_{T}$ the highest error is about $12 \%$.

Table 3: Experimental and numerical thrust coefficient.

\begin{tabular}{|c|c|c|c|c|c|c|c|}
\hline \multicolumn{4}{|c|}{$C_{\mu}=0$} & \multicolumn{4}{|c|}{$C_{\mu}=0.5$} \\
\hline$V_{\text {eng }}(\mathrm{m} / \mathrm{s})$ & $\mathrm{C}_{\mathrm{TCFD}}$ & $\mathbf{C}_{\mathrm{T} \text { exp }}$ & \% Error & $V_{\text {eng }}(\mathrm{m} / \mathrm{s})$ & $\mathrm{C}_{\mathrm{TCFD}}$ & $\mathbf{C}_{\mathrm{T}_{\exp }}$ & \% Error \\
\hline 28.98 & 0.027 & 0.024 & 11.95 & 46.59 & 0.070 & 0.062 & 12.03 \\
\hline 47.21 & 0.072 & 0.064 & 11.74 & 107.58 & 0.377 & 0.341 & 10.48 \\
\hline 76.94 & 0.192 & 0.173 & 11.1 & 174.66 & 1.022 & 0.953 & 7.3 \\
\hline 106.66 & 0.371 & 0.337 & 10.19 & 240.6 & 2.027 & 1.974 & 2.7 \\
\hline 123.27 & 0.499 & 0.455 & 9.55 & 297.15 & 3.256 & 3.338 & 2.46 \\
\hline 156.59 & 0.817 & 0.756 & 7.98 & & & & \\
\hline 191.67 & 1.247 & 1.178 & 5.93 & & & & \\
\hline 225.03 & 1.758 & 1.697 & 3.59 & & & & \\
\hline 257.62 & 2.364 & 2.341 & 0.98 & & & & \\
\hline 283.87 & 2.939 & 2.981 & 1.4 & & & & \\
\hline
\end{tabular}

Figure 17 shows the lift curves for two different $C_{\mu}$ values. It can be seen again that the higher $C_{\mu}$ yields a higher relative error in $C_{L}$, about $30 \%$, while the lower $C_{\mu}$ is pretty close to the experimental everywhere except approaching stall. This figure also shows the turbulence model's inability to model the stall regime. According to Bell of Fluent Inc $^{17}$ the $k-\varepsilon$ turbulence model over-predicts the turbulent kinetic energy which delays separation. Therefore, the separation observed in the stall regime is not accurately captured. Further investigation of different turbulence models must be performed to determine the best model for the stall regime. 


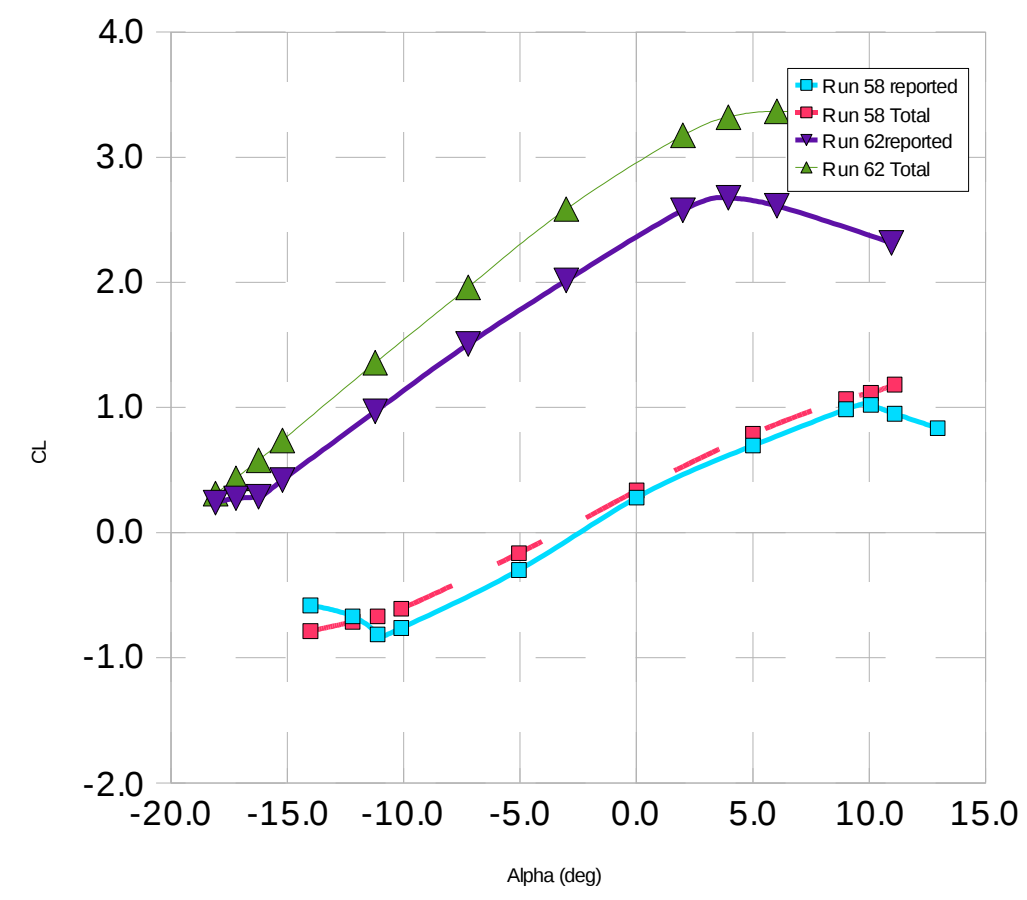

Figure 17: Configuration B lift curves at $q=5.5 p s f$.

\section{B. Grid Independence Study}

A grid independence study was also performed to determine a grid size acceptable for this validation. The results of the three different meshes are shown on Table (4). Figure (18) and (19) show the convergence of the different meshes towards the extrapolated solution as given by the Richardson Extrapolation for the lift and drag coefficient. The errors associated with these solutions are also plotted on the grid points. Although the finer mesh yields a $C_{L}$ much closer to the extrapolated solution, the intermediate mesh was used mostly because of faster residual convergence.

Table 4: Calculation of GCI and discretization

error.

\begin{tabular}{c|cc} 
& Lift Coefficient & Drag Coefficient \\
\hline $\mathbf{N}_{1}$ & $3.97 \times 10^{6}$ & $3.97 \times 10^{6}$ \\
$\mathbf{N}_{2}$ & $7.11 \times 10^{6}$ & $7.11 \times 10^{6}$ \\
$\mathbf{N}_{3}$ & $8.64 \times 10^{6}$ & $8.64 \times 10^{6}$ \\
$\mathbf{r}_{12}$ & 1.21 & 1.21 \\
$\mathbf{r}_{23}$ & 1.07 & 1.07 \\
$\boldsymbol{\phi}_{1}$ & 1.732 & 0.0499 \\
$\boldsymbol{\phi}_{2}$ & 1.708 & 0.0454 \\
$\boldsymbol{\phi}_{3}$ & 1.691 & 0.0444 \\
$\mathbf{n}$ & 5.59 & 1.50 \\
$\boldsymbol{\varphi}_{\infty}$ & 1.6549 & 0.0349 \\
$\mathbf{e}_{\text {app }}$ & 0.0095 & 0.0221 \\
$\mathbf{e}_{\infty}$ & 0.0221 & 0.275 \\
$\mathbf{G C l}$ & 0.027 & 0.269
\end{tabular}




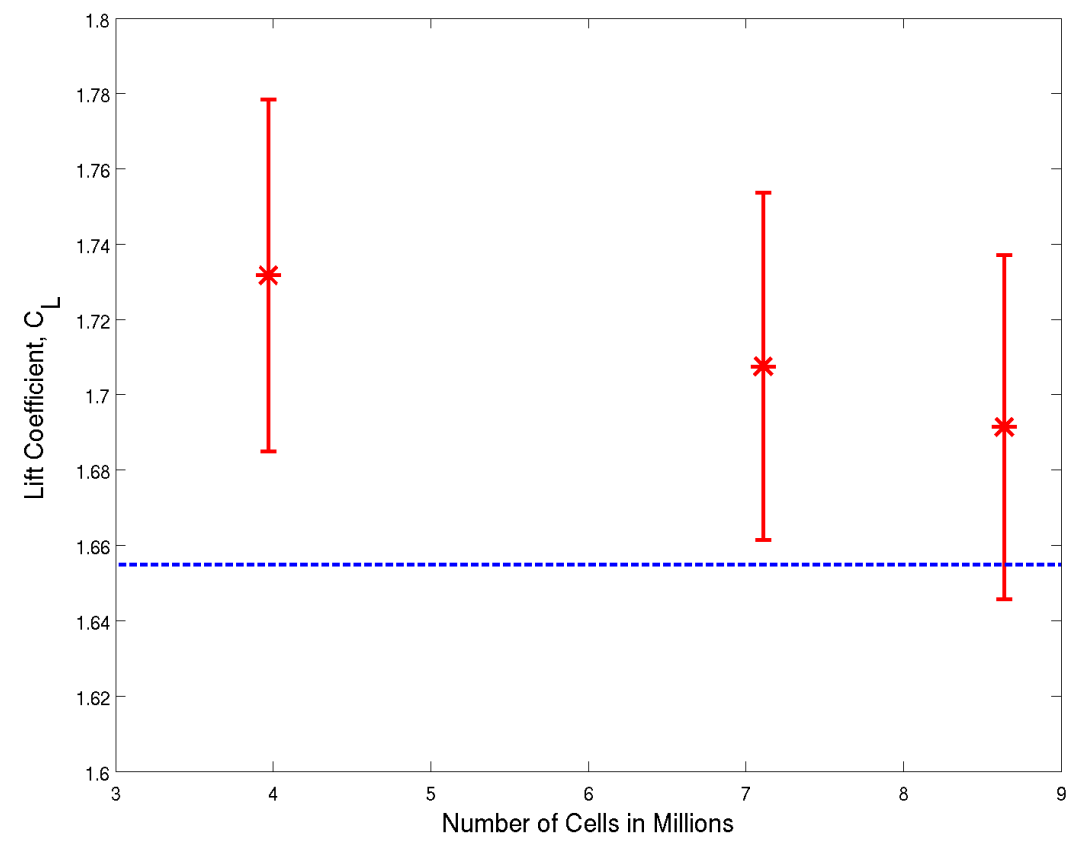

Figure 18: Convergence of lift coefficient towards the extrapolated solution as mesh size increases.

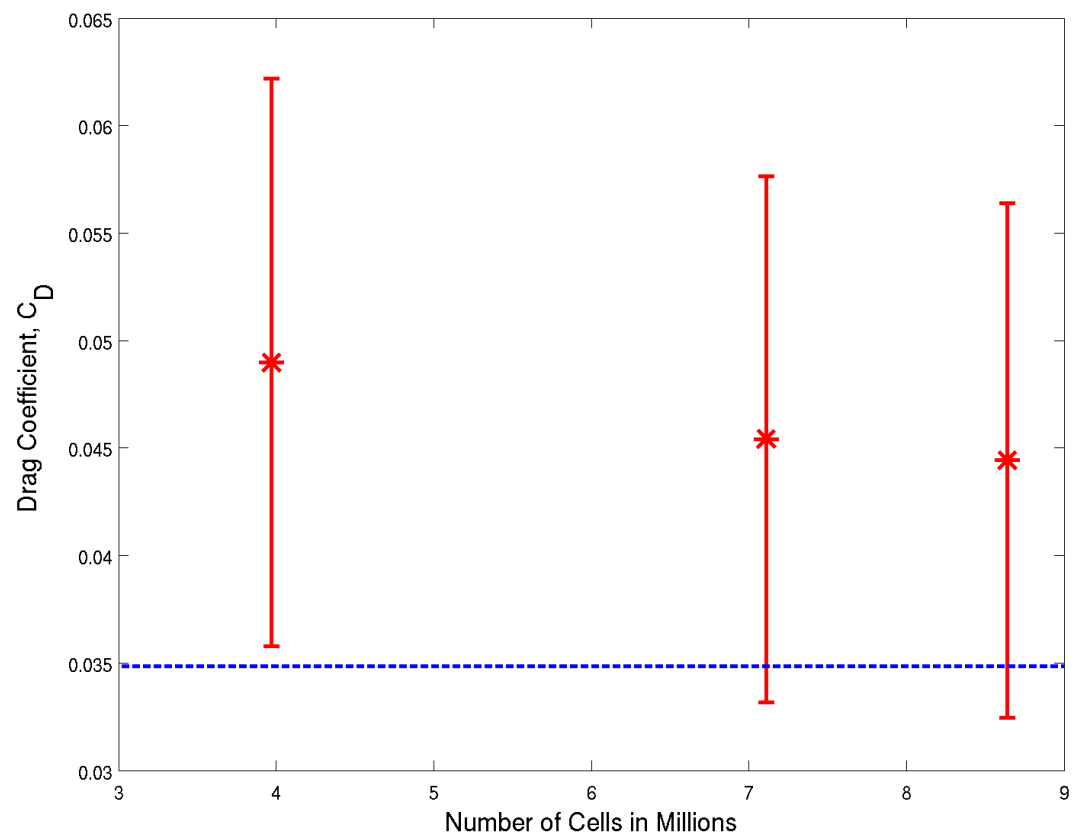

Figure 19: Convergence of drag coefficient towards the extrapolated solution as mesh size increases. 


\section{Residual Convergence}

An example of the convergence history is shown in Figure 20. The large spikes around 1000 iterations result from the solution being changed from first oder to second order upwind. The solution was then iterated enough times until there was insignificant change in the residuals, or until they became fairly horizontal.

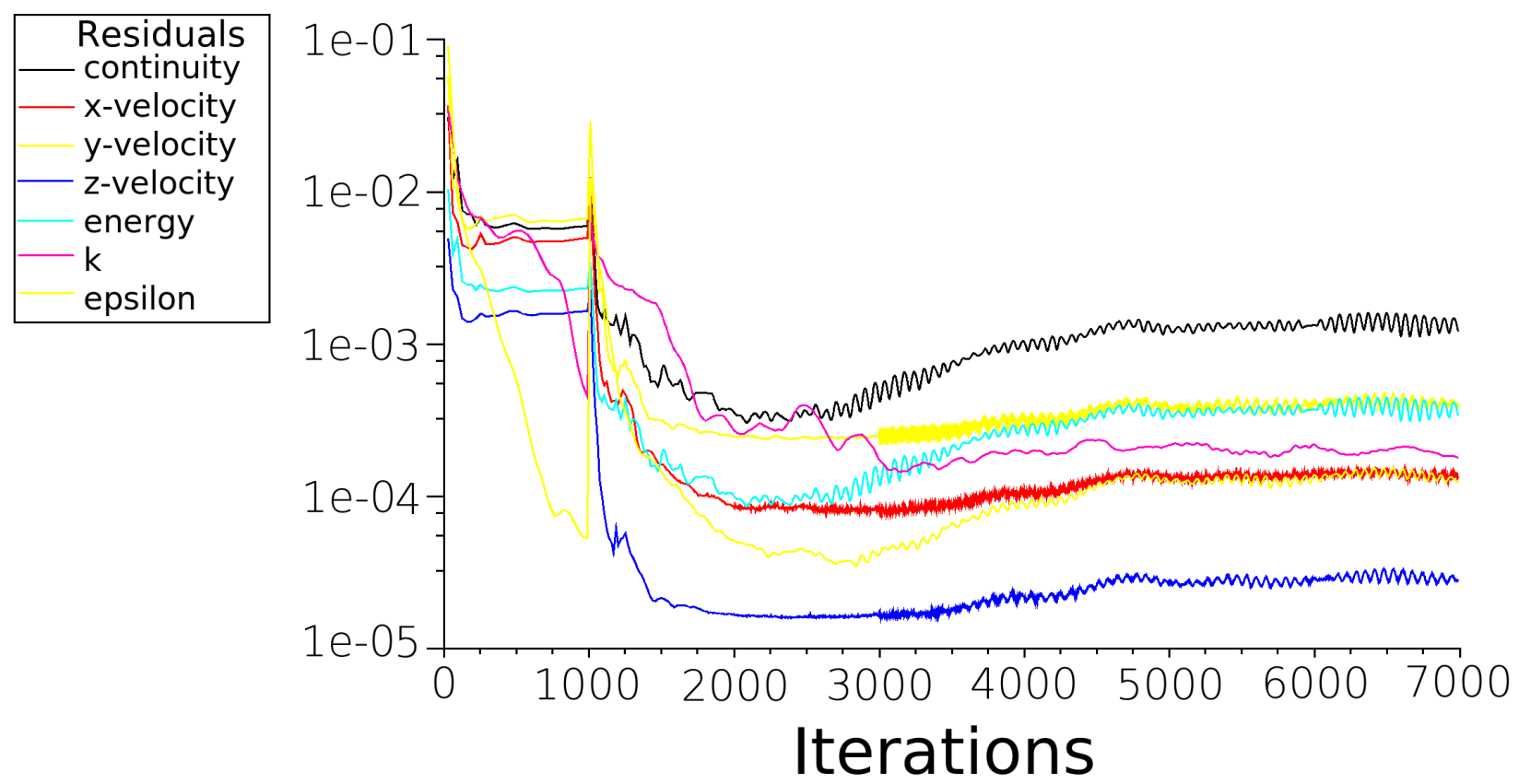

Figure 20: Typical convergence history.

\section{Flow Visualization}

Figure 21 shows earlier evaluations of similar powered-lift models in the same MTF tunnel presented by Englar et al. ${ }^{1}$, which was used as the basis of GTRI's aerodynamic testing. The flow visualization shows the deflection capability of the engine thrust caused by the entrainment of the engine exhaust flow by the CCW flap. Similar results were obtained from CFD analysis of Configuration B. Fig (22) shows similar deflection of the engine thrust caused by the entrainment of the engine exhaust. The engine static thrust deflection observed in Fig (22) does not exactly match the thrust deflection shown in Fig (21) because of multiple reasons. It is currently unknown where the engine of the original model was positioned compared to the surface of the wing and the CCW slot. For this reason, $\mathrm{x} / \mathrm{C}$ and $\mathrm{z} / \mathrm{D}$ may be different between the two models. Also, Configuration B has no CCW flap deflection. This causes a smaller engine exhaust deflection angle for Configuration B. The main purpose of presenting these two figures is to show that engine thrust deflection is still present in the CFD analysis. 


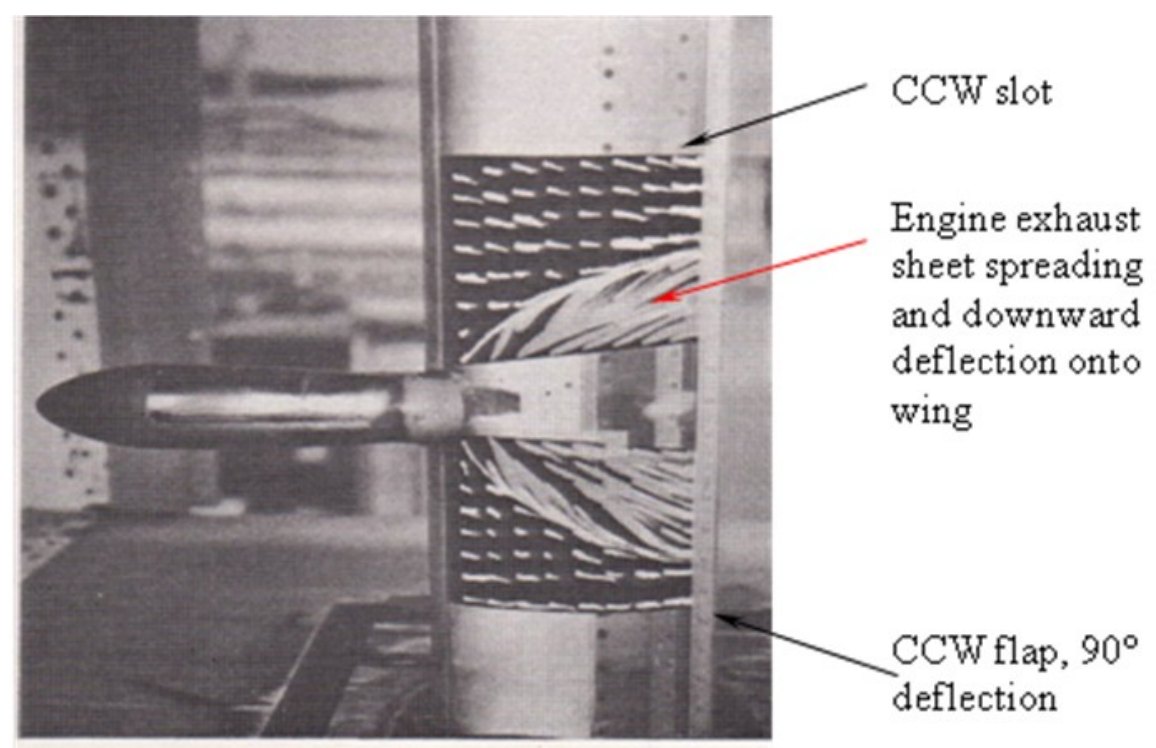

(e) $C_{T}=1.21, C_{\mu}=0.47$

Figure 21: CCW/OTW model with jet flow entrainment shown by flow visualization from Englar et al. ${ }^{1}$

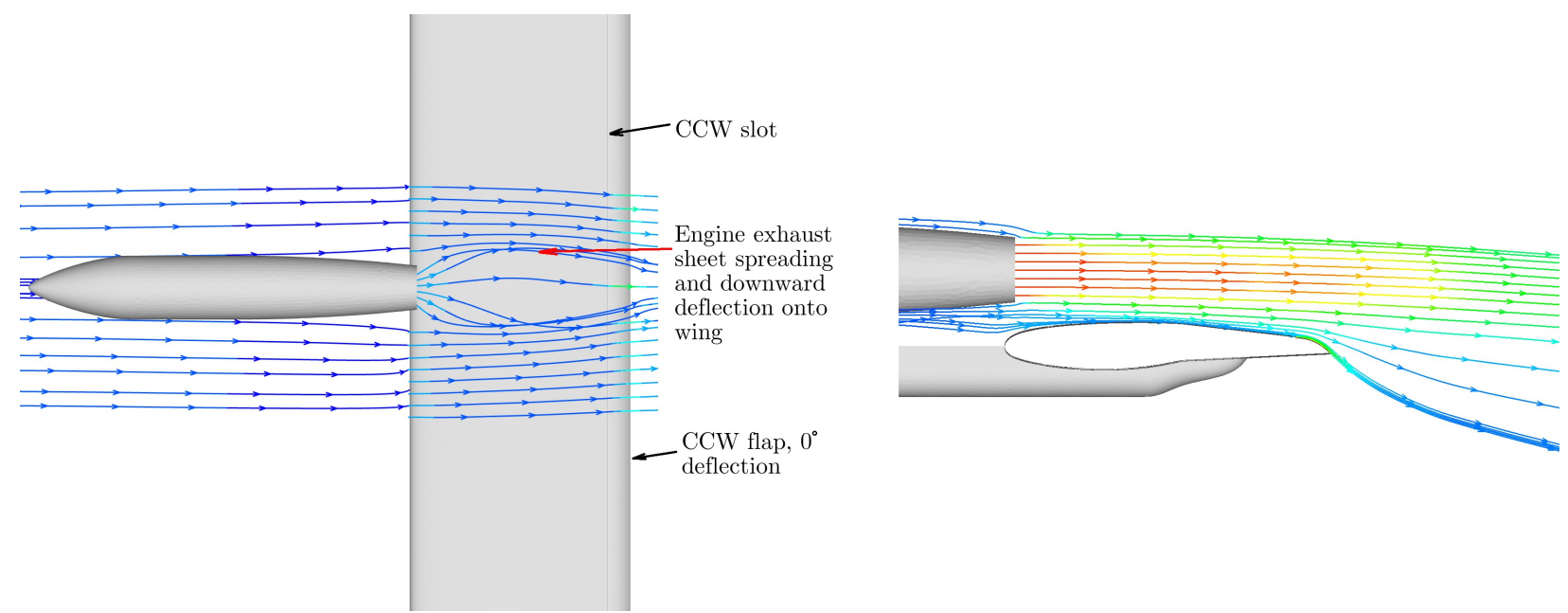

Figure 22: Configuration $B$ with jet flow entrainment shown by streamlines. Streamlines are colored by increasing velocity magnitude from blue to red. $C_{T}=2.1, C_{\mu}=0.631$ 


\section{Conclusion}

This paper presented CFD methods in validating experimental data of a circulation control airfoil coupled with upper surface blowing from a 3D engine. The motivation behind this validation is to develop grid generating and solving techniques that will be applied to future CFD analysis of other aircraft configurations equipped with over the wing engine and circulation control. Numerous validations have been performed on circulation control airfoils and its been seen numerous times that current CFD codes over-predict lift and drag coefficient of the airfoil because of the code's inability to match the jet separation and the streamline turning of the jet exhaust. This failure was linked to the available turbulence models and CFD grid issues. This paper focused mostly on grid generation using Ansys ICEM and utilized FLUENT's $k-\varepsilon$ turbulence model.

This validation was performed on a single configuration to determine the effects of variations in thrust coefficient and blowing momentum coefficient on lift and drag. Thrust coefficient ranged from 0 to 3.36 and blowing momentum coefficient ranged from 0 to 0.62 . Aerodynamic test results showed that the grid generation method presented in this paper and the use of $k-\varepsilon$ turbulence model still over-predicted lift and drag coefficient. These results agreed with the general trend found in using two-equations turbulence models, such as the $k-\varepsilon$ turbulence, in which $C_{L}$ is overpredicted as $C_{\mu}$ increases. At a constant thrust coefficient, lift was over-predicted by approximately $12 \%$ at the lowest momentum coefficient but increased to approximately $20 \%$ at the highest momentum coefficient. Similarly, at a constant momentum coefficient, lift is over-predicted by approximately $15 \%$ at the lowest thrust coefficient and increases to approximately $25 \%$ at the highest thrust coefficient.

Validating the experimental thrust and blowing momentum coefficients was important to ensure that the flow features of the exhaust and jet velocity were accurately captured. Results showed that the relative error in thrust coefficient decreased at higher thrust coefficients. Similarly, the relative error in momentum coefficient decreased at higher momentum coefficients only if the exhaust from the engine was present. At a thrust coefficient of zero, the relative error of the momentum coefficient actually increased at higher momentum coefficients. This was linked to the difference in how the experimental $C_{\mu}$ and the CFD $C_{\mu}$ were calculated. When $C_{T} \neq 0$, the process in which the CFD $C_{\mu}$ was calculated became more and more similar to the calculation of the experimental $C_{\mu}$.

Results of this validation strongly agree with other literature that grid issues and turbulence models caused an overprediction of the lift and drag coefficients. Even with the added complexity of an engine, the results still followed the general trend that is seen from two-equation turbulence models. Future work will utilized FLUENT's existing turbulence models as well as the $v^{2-} f$ turbulence model that is currently being developed to be used in FLUENT. It is expected that by utilizing new turbulence models, the over-prediction of $C_{L}$ and $C_{D}$ will be reduced. Future analysis will combine the meshing techniques developed in this investigation and a turbulence model with better predictive capability to further reduce the error in computing $C_{L}, C_{D}, C_{\mu}$, and $C_{T}$.

\section{Acknowledgments}

This work was funded as part of a NASA Research Announcement award under Contract \#NNL07AA55C with Craig Hange and Clif Horne as the technical monitors. The authors also wish to thank the hard work of Bryan Blessing, Fletcher Hartshorn, Rory Golden, John Pham, and Travis Storm.

\section{References}

1. Englar, R. J., Gaeta, R. J., Lee, W. J., and Leone, V., "Development of Pneumatic Over-the-Wing Powered-Lift technology; Part I: Aerodynamic/Propulsive" Submitted to 27 $7^{\text {th }}$ AIAA Applied Aerodynamics Conference, Georgia Tech Research Institute, Atlanta, GA, June 2009.

2. Pham, J., and Marshall, D. D., "Predictive Modeling Using CFD on a Circulation Control Aircraft for Wind Tunnel Validation," Submitted to $48^{\text {th }}$ AIAA Aerospace Sciences Meeting, California Polytechnic State University, San Luis Obispo, CA, May 2009.

3. Englar, R. J., "Subsonic Two-Dimensional Wind Tunnel Investigations of the High Lift Capability of Circulation Control Wing Sections,” DTNSRDC Report ASED-274, April 1975.

4. Harris, M. J., Nichols, J. H., Jr., Englar, R. J., "Development of the Circulation Control Wing/Upper Surface Blowing Powered-Lift System for STOL Aircraft," Paper No. ICAS-82-6.5.1 presented at the $13^{\text {th }}$ Congress of ICAS/AIAA Aircraft Systems and Technology Conference, Seattle, Aug. 1982. 
5. Blessing, B., and Marshall, D. D., "A Computational Study of Entraining Engine Flow Using a Circulation Control Wing” Submitted to $48^{\text {th }}$ AIAA Aerospace Science Meeting, California Polytechnic State University, San Luis Obispo, CA, May 2009.

6. Golden, R., and Marshall, D. D., "Design and Performance of Circulation Control Dual Radius Flap Systems" Submitted to $48^{\text {th }}$ AIAA Aerospace Science Meeting, California Polytechnic State University, San Luis Obispo, CA, May 2009.

7. Ansys ICEM $\underline{\text { CFD, }}$ Software Package, Vers. 11.0.1. < $\underline{w w w . a n s y s . c o m}>$

8. Ansys FLUENT, Software Package, Vers. 6.3.26, Fluent Inc. < $\underline{\text { www.ansys.com }>}$

9. Englar, R. J., "Development of Circulation Control Technology for Powered-Lift STOL Aircraft," Lockheed Georgia Company, May 1987.

10. Storm, T. M. , and Marshall, D. D., "Assesing the $v^{2}-f$ Turbulence Models for Circulation Control APplications," Submitted to $48^{\text {th }}$ AIAA Aerospace Sciences Meeting, California Polytechnic State University, San Luis Obispo, CA, May 2009.

11. Spalart, P. R., and Allmaras, S. R., “A One-Equation Turbulence Model for Aerodynamic Flows,” AIAA Journal vol. 26, pp 1299-1310, 1988.

12. Harlow, F. H., and Nakayama, P. I., “Transport of Turbulence Energy Decay Rate,” Los Alamos Sci. Lab., LA-3854, 1968.

13. Wilcox, D. C., "Reassessment of the Scale-Determining Equation of Advanced Turbulence Models, AIAA Journal vol. 26, pp. 1299-1310, 1988.

14. Durbin, P. A., Near-Wall Turbulence Closure without 'Damping Functions'," Theoretical and Computational Fluid Dynamics 3:1-13, 1991.

15. Celik, I. B., Ghia, U., Roache, P. J., and Freitas, C. J., "Procedure for Estimation and Reporting of Uncertainty Due to Discretization in CFD Applications," Journal of Fluids Engineering.

16. Jones, G. S., Lin, J. C., Allan., B. G., Milholen, W. E., Rumsey, C. L., Swanson, R.C., "Overview of CFD Validation Experiments Circulation Control Applications at NASA," 2008 International Powered Lift Conference, 22-24 Jul. 2008, London, United Kingdom.

17. Bell, B., "Turbulent Flow Case Studies," Fluent Software Training, Fluent Inc. Fluent User Services Center, $<$ www.fluentusers.com> 


\begin{tabular}{|c|c|c|c|c|c|c|c|c|c|c|}
\hline Config & $\delta_{\text {flap, }}{ }^{\circ}$ & $\delta_{\mathrm{LE}}{ }^{\circ}$ & $x / C$, eng & $x_{\mathrm{te}} / \mathrm{D}$ & $\mathrm{z} / \mathrm{D}$, eng & $\phi_{\text {hood, }}{ }^{\circ}$ & $\mathrm{h}_{\mathrm{CCW}}$, in & Runs & $\mathrm{C}_{\mathrm{L}}$ & $\mathrm{C}_{\mathrm{D}}$ \\
\hline $\mathrm{A}$ & 0 & 0 & 0.75 & 1.3538 & 0.23 & Off & 0.02 & $11-54$ & 2.47 & -2.305 \\
\hline B & & 1 & 0.03 & 5.2529 & 0.37 & $"$ & 1 & $55-75$ & 2.64 & -2.44 \\
\hline $\mathrm{C}$ & & & $"$ & " & $"$ & 15 & & $76-91$ & 3.53 & -2.4 \\
\hline $\mathrm{D}$ & & & $"$ & $"$ & $"$ & 30 & & $92-108$ & 4.28 & -2.36 \\
\hline$E$ & & & $"$ & $"$ & 12 & Off & & $100-121$ & 2.51 & -2.52 \\
\hline $\mathrm{F}$ & & & $"$ & $"$ & $"$ & 30 & & $122-134$ & 3.89 & -2.48 \\
\hline $\mathrm{G}$ & & & 0.75 & 1.3538 & $"$ & Off & & $135-147$ & 2.46 & -2.45 \\
\hline $\mathrm{H}$ & & & $"$ & " & $"$ & 30 & & $148-160$ & 3.63 & -2.57 \\
\hline I & & & 0.25 & 4.0615 & 12 & Off & & $161-164$ & 2.44 & -2.50 \\
\hline $\mathrm{J}$ & & & $"$ & $"$ & $"$ & 30 & & $165-171$ & 3.83 & -2.52 \\
\hline $\mathrm{K}$ & & & $"$ & $"$ & 0.31 & Off & & $172-178$ & 2.55 & -2.4 \\
\hline $\mathrm{L}$ & $\nabla$ & $\forall$ & $"$ & $"$ & $"$ & 30 & & $179-189$ & 4.06 & -2.31 \\
\hline $\bar{M}$ & 90 & 0 & 0.25 & 4.0615 & 0.31 & 30 & & $190-205$ & 5.55 & -1.27 \\
\hline $\mathrm{N}$ & & 60 & 0.25 & 4.0615 & 0.31 & 30 & & $206-215$ & 6.41 & -1.11 \\
\hline $\mathrm{O}$ & & & $"$ & " & $"$ & $\overline{\mathrm{Off}}$ & & $216-222$ & 5.96 & -1.44 \\
\hline $\mathrm{p}$ & & & 0.03 & 5.2529 & 0.37 & Off & & $223-233$ & 6.11 & -1.47 \\
\hline $\mathrm{Q}$ & & & $"$ & " & $"$ & 30 & & $234-243$ & 6.53 & -1.13 \\
\hline $\mathrm{R}$ & & & 0.75 & 1.3538 & 0.23 & Off & & $244-255$ & 5.95 & -1.47 \\
\hline $\mathrm{S}$ & & & $"$ & $"$ & $"$ & 30 & & $256-265$ & 7.06 & -1.51 \\
\hline $\mathrm{T}$ & & & $"$ & $"$ & 12 & Off & & $266-277$ & 4.68 & -1.57 \\
\hline$\overline{\mathrm{U}}$ & & & $\bar{m}$ & $\bar{m}$ & 12 & 30 & & $278-287$ & 6.00 & -1.75 \\
\hline $\mathrm{V}$ & & & 0.25 & 4.0615 & 12 & Off & & $288-300$ & 5.14 & -1.57 \\
\hline $\mathrm{W}$ & & & $"$ & $"$ & 12 & 30 & & $301-310$ & 7.31 & -1.47 \\
\hline $\mathrm{X}$ & & & 0.03 & 5.2529 & 12 & $\mathrm{Off}$ & & $334-343$ & 5.08 & -1.58 \\
\hline $\mathrm{Y}$ & & & $"$ & " & 12 & 15 & & $324-333$ & 5.93 & -1.67 \\
\hline $\mathrm{Z}$ & & & $"$ & $"$ & 12 & 30 & & $314-323$ & 6.95 & -1.47 \\
\hline $\mathrm{AA}$ & & & $"$ & $"$ & 0.7 & Off & & $356-365$ & 5.26 & -1.54 \\
\hline $\mathrm{BB}$ & & & $"$ & " & 0.7 & 30 & $\checkmark$ & $346-355$ & 6.55 & -1.18 \\
\hline $\mathrm{CC}$ & & & 0.03 & 5.2529 & 0.7 & Off & 0.01 & $357-376$ & 5.33 & -1.53 \\
\hline $\mathrm{DD}$ & & & $"$ & " & 0.7 & 15 & 1 & $377-386$ & 6.96 & -1.42 \\
\hline $\mathrm{EE}$ & & & 0.03 & 5.2529 & 0.7 & 30 & & $387-403$ & 7.22 & -1.14 \\
\hline $\mathrm{FF}$ & & & 0.25 & 4.0615 & 0.7 & 30 & & 404-415 & 7.43 & -1.32 \\
\hline GG & $\Downarrow$ & $\forall$ & 0.75 & $1.35 \mathbf{8}$ & 0.7 & 30 & & $416-427$ & 7.02 & -1.73 \\
\hline $\mathrm{HH}$ & 30 & 60 & 0.75 & 1.353 & 0.7 & 30 & 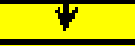 & $431-436$ & 5.9 & -2.5 \\
\hline II & 30 & 60 & 0.25 & 4.0615 & 0.58 & 30 & 0.01 & $437-446$ & 6.51 & -1.97 \\
\hline $\mathrm{JJ}$ & 30 & 60 & 0.03 & 5.2529 & 0.7 & 30 & 0.01 & $447-452$ & 6.93 & -1.81 \\
\hline KK & 30 & 60 & 0.25 & 4.0615 & 0.5 & 15 & 0.01 & $453-462$ & 5.37 & -2.39 \\
\hline
\end{tabular}

Appendix 1: Geometry specifications on all 37 configurations. 